\title{
Shedding Light on Colorism: How the Colonial Fabrication of Colorism Impacts the Lives of African American Women
}

\author{
Adeola Egbeyemi
}

$D^{1}$ FFERENT individuals define the start of summer by different moments. It may be the joyous completion of final exams for one or the excitement of packing for vacation for another. Even the change of one's outfit into billowing tops and high-waisted denim shorts might signify the beginning of the hottest season of the year. However, the start of my summer is typically linked to one comment: "Don't get too dark."

This is as overt as the statement gets. In my life, it is the unspoken statements which are the most prevalent. From the African beauty shops downtown that slip lightening creams into your final purchase, to cosmetic foundations tailored to lighter shades, examples of internal and external prejudice against individuals with a darker skin tone are ubiquitous. This manifestation of prejudice is termed colorism, first coined by African American novelist and civil rights activist Alice Walker as the "prejudicial or preferential treatment of same-race people based solely on their colour" (290).

Although the phenomenon of colorism is pervasive, meaningful discussion of its impact has been historically neglected. In the novel Same Family, Different Colors, dark-skinned professor, author, and journalist Lori L. Tharps identifies that the lack of open discussion on colorism is common in households where seemingly "more significant" issues take precedence. Black families often aim to keep the focus on racism, an issue the whole family would face as opposed to the additional inequality faced by specific darkerskinned members (Tharps 38). This same lack of discussion frequently applies beyond the familial sphere. Therefore, it is necessary to allow the analysis of colorism to have the same academic priority as is given to the analysis of other inequalities, such as racism. Considering this, I argue that the colonial fabrication of colorism is pervasive and not only does it impact the aesthetic perception of African American women, but it also determines their socio-economic status and life outcomes.

I hold this position as, firstly, colorism is often seen as a divisive issue within the African American community in the United States, pitting dark-skinned peoples against the lighterskinned members of their own race. These interactions and definitions fail to include the historical context: specifically, how colorism's fabrication was systemically enforced and ingrained within the Black community through white colonial ideals perpetuated during the Atlantic slave trade. Understanding America's history of colonialism and slavery is essential to understanding colorism in African American communities. It then follows that the unpacking of the historical 
context of colorism's creation is crucial to the exploration of this topic.

I also maintain my position since contemporary discussion of colorism between lighterskinned and darker-skinned black women is often, yet inaccurately, boiled down to a "she's seen as pretty, and she's not" issue. Recognizing that being dark-skinned is another socioeconomic disadvantage — in addition to being African American and being a woman - is crucial to understanding the impact of colorism on the life of a dark-skinned African American woman.

For this paper, I conducted a secondary data analysis of essays and novels written primarily by African American female academics. This coupling is an example of integrative knowledge derived from the mix of both lived experiences and academia. Black women wrote many of the sources used in this research about black women, providing a research base rich in situated knowledge. When scouring for sources, I did not actively seek the specific social location of "dark-skinned African American female" author; however, once identified as such, it was given greater weight within this paper. Using sources that featured firsthand knowledge of the physical and mental experiences of living as a dark-skinned woman proved to be useful. These authors' experiences yielded direct, viable knowledge and insights in addition to their research and studies, resulting in more profound observations; third-parties may know these states only by interpreting visible symptoms or learning from testimonies.

This essay integrates history and human sciences by unpacking the slave-buyer mentality from the Atlantic slave trade and the resulting African American woman's life from that era onward.

\section{I: Colorism from the Colonial ERA tO}

\section{The 20Th Century}

Colonialism within the 'New World'1 played an instrumental role in engineering the American preference for those with white or light black skin. The enslavement and systematic oppression of dark-skinned individuals perpetrated this preference. African American law professor Kimberly Jade Norwood distinguishes that although "slavery was not invented in the New World...", it became so deeply associated with dark skin that "... it was almost impossible to separate the two" (592). It is essential to recognize that slavery existed long before the enslavement of African peoples, but that the effects of slavery in America almost inextricably linked black skin to slave status. When the colonial empire was faced with an agricultural "need for a controllable and cheap labour force" for the likes of tobacco harvesting or cotton picking, slavery laws were passed, and the dehumanization of enslaved Africans began (Norwood 592). It is important to note that in the early years of American slavery, enslaved Africans in the Virginia and Carolina colonies could be freed if they followed specific regulations, such as conversion to Christianity. This loophole was eliminated after 1667, firmly ingraining the legal status of enslaved Africans to their skin colour (Norwood 592). By the late 17th century, "white skin came to be synonymous with freedom and black skin with slavery" and, therefore, skin tone played a clear role within the emergence of a hot, new, and profitable business: the slave market (Norwood 592).

According to American historian and African studies professor Walter Johnson in the novel Soul by Soul: Life Inside the Antebellum Slave Market, a savvy slave buyer knew to "... look past the fancy clothes, bright faces, and promising futures" (137) of enslaved Africans lined up before buyers. In fact, buyers knew nothing "as to the character and disposition" of the enslaved and could "... only judge the looks of the Ne-

\footnotetext{
${ }^{1}$ New World is placed within quotations because although European colonizers saw the Americas as a new addition to the world, it would be incognizant to not acknowledge the longevity and richness of culture that existed long before discovery.
} 
groes" (138). Thus, the looks of the enslaved provided all the evidence deemed necessary to infer how a slave would behave. It would logically follow that skin colour would be the first visual marker of these projected qualities.

The discrepancy of black skin colour in America first arose when sexual unions began between enslaved African women and their white male captors. These unions produced children who were preferred by white society over their darker-skinned brethren. The various and specific words slave buyers used for lighter skin colour were 'mulatto', a dated term for an individual of mixed black and white ancestry, 'quadroon', for an individual who was one-quarter black, 'octoroon', one-eighth, and so forth (Johnson 138). These terms indicate the importance that buyers placed on skin colour, especially since the categories of skin tone in the United States census at the time were limited to 'black' and 'mulatto' (Johnson 138).

In the Antebellum South, "a disproportionate amount of light-skinned women" (Johnson 151) were chosen for the role of domestic servants. A slave trader's 1859 letter claiming "the girls are brownskin and good house girls" (Johnson 157) gives an example to how light skin tones were valued. Skin colour is referred to first, and the claim that they are "good house girls" follows from this physical marking. Johnson notes that the bodies of light-skinned women were frequently referred to as 'delicate' by slaveholders. These women, delicate due to the "whiteness" in their blood, were deemed "ill-suited for the daily rigours [demanded] of dark-skinned women" (Johnson 152) and their high rates of placement in domestic roles followed from this. In the minds of slave buyers, there existed a strong association between the colour of one's skin and the type of service to which they were suited. In addition to the perceived outer delicacy and inner intelligence, the "racial gaze" (Johnson 155) of the slaveholder added value to the body of light-skinned women for sale. In a recorded description of an enslaved woman by the name of Mildred Ann Jackson:
"... she was about thirty... her colour was that of a quadroon; very good figure, she was rather tall and slim... had a mole on her upper lip. Her hair was straight," (Johnson 155), one saw buyers directly buying predominately white features such as 'straight hair.' The 'hybrid whiteness' of such enslaved people was first assessed by traders and then inferred into meanings of delicacy, beauty, intelligence - what was mere "dreamy interpretations of the meaningfulness of [the buyer's own] skin colour" (Johnson 155). Women described as such went for high prices in the market, indicating that light skin was an indication of social status in white slave buying communities, and thus in the general Caucasian population, before it was in Black communities. However, this skin tone stratification became complicated as White communities began to fear that light-skinned black women were threatening the primacy of pure whiteness. This complexity kept light-skinned black woman contained within the enslaved Black community.

These fundamental dynamics of lighterskinned and darker-skinned women remained distinct even after the physical liberation of enslaved African Americans in the Civil War. According to African American anthropologist and sociologist, Margaret Hunter, individual freedoms that white slave owners gave to enslaved lighter-skinned Africans, such as "the occasional opportunity to learn to read, and the rare chance for manumission" (Hunter 239), led to the creation of a small, elite class of freedmen. These "disproportionately light-skinned men and women were the early clergy leaders, business people, teachers, and artisans who became economic and community leaders in the early African American community" (Hunter 239). This disproportionality was seen in the education of black individuals in the late 1880s, when in the District of Washington, for example, sixty percent of 'mulatto' heads of households could read, whereas only twenty percent of black heads of households could assert the same (Kerr 277). The influx of liberated black individuals into neighbourhoods created highly impoverished environments, as they rarely had 
enough money or education to survive. The welleducated 'mulattos' were able to withdraw from these 'darker classes' because of their education (Hunter 239).

This attempt by light-skinned black individuals to move into white spaces gave rise to the first social complexion tests, detailed by African American literature professor Audrey E. Kerr. These tests were "racial confrontations by whites to keep fair blacks from 'passing' into white organizations, institutions and even white families" (Kerr 277). In the late 19th and early 20th century, these tests involved the examination of phenotypic qualities, such as nail beds, where black blood was claimed to be "evidenced by a purplish semicircle on the nail beds of a person of colour" (Kerr 277). Other tests included an examination of hair roots for the "telltale kink in the fair hair" (Kerr 278). This initial testing served as a reminder to light-skinned or whitepassing African Americans that any indication or hint of blackness was enough to deny them access into places of higher status.

Moving to the 1920s, spotting' tests were the second form of testing that "solicited the assistance of blacks to identify members of the Black community who were passing into White communities" (Kerr 278). These black men and women were placed outside of white establishments to spot black people, especially mixed-race people who might be hard to differentiate. At this time, it became clear that colorism had been internalized in some ways; testing was done by some African American people to keep others of the same race out.

The final form these complexion tests took was random testing, often known as the 'paper bag test.' During African American gatherings at bars, churches, or parties deemed as paper bag events, one had to be lighter than the bag to get in. Kerr offers an insightful testimony from a New Orleans interviewee. The interviewee distinguishes that no physical comparisons between a woman's skin and a paper bag were made in order to enter a party (283). Instead, if you came inside as a dark-skinned woman, the interviewee claims, no men would dance with you, people would stare - it would be like crashing the party (283). They state that "it was understood that it was a brown bag party. In the culture, you just knew it" (Kerr 282). Numerous accounts of similar sentiments paint a picture of the complete internalization of colorism by the Black community. Within Black community events, there became an explicit, internalized status quo where lighter-skinned people were preferred. This divide has continued to the present day.

Through this timeline, colorism has been unpacked as an elitist ideal not only created by the non-marginalized but also ingrained into the ideals of the marginalized. With the background for the colonial creation of this preference for lighter skin colour, we can see how deep-rooted colorism is within the African American community, as it is a legacy of the colonial past.

\section{II: Colorism in Beauty and Socioeco- NOMIC Status}

Colorism has been able to influence many spheres of life through the significant presence of technology and media in today's society. Within the sphere of media representation, according to African American author Sharon BramlettSolomon's book on Race, Gender, Class and Media, "lighter-skinned black women are represented in all forms of advertising (store advertisements, magazines, billboards) and television (as news anchors, love interests, commercial models)" (Norwood 594). In Hollywood, the preference for light-skinned women of colour is evident, as it is rare to find a dark-skinned woman in a positive leading role or as a love interest. Consider Zoe Saldana, the 'café au lait' coloured actress who was cast to play Nina Simone in Nina (Norwood 594). For the film, dark makeup was applied daily so light-skinned Saldana could look more like the dark-skinned Nina Simone. This example perpetuates the current notion that lighter skinned black women will always be the default for the silver screen, to the point 
of putting in extra effort to make them seem dark-skinned. What is crucial to observe is that this example is within the same ongoing system of white dominance. In the case of the movie Nina, the director, casting director, makeup and prosthetic artists, and all producers except two were white. It is thus understandable, or at least unsurprising, that persons in positions of power - often Caucasian and male - select these images in these examples, demonstrating the same colonial dynamic of displaying their own features of whiteness.

Norwood describes that "lighter skinned women... were [also] more likely to be featured in editorial photos and advertisements from the [19]60s through the 90s" (Fultz 19) of blackowned resources, such as Ebony or Jet magazine. Although representation in these editorials had a higher balance of dark- and light-skinned African American women, "descriptors such as "pretty, lovely, and beautiful' were substantially more likely to be paired with images of lighter, more Eurocentric looking women," (Fears 20). The internalization of colorism is thereby outlined here, in that the value of beauty for lighterskinned African American women, created by white Americans, is now locked into the ideals of African Americans. Other spheres of African American culture, such as the music industry, display this internalization. Within African American Ph.D. candidate Lauren A. Fultz's dissertation paper on "The Psycho-Social Impact of Colorism Among African American Women", she discusses skin tone and media representation. Most notably in rap and R\&B, Fultz discusses how music videos are more likely to contain images of "idealized African American women, who tend to have lighter skin" (19), again demonstrating how people have internalized the notion that lighter skinned women are more beautiful.

Furthermore, it is interesting to note how intertwined colorism and sexism are. The perception of light-skinned black women as more attractive also impacts how dark-skinned women date and marry. According to Fultz, "...complexion hierarchy is more central in the lives of women than men" because society not only places high societal value on women's beauty but also places "whiteness of skin [as a] highly valued... dimension of beauty" (20). The relationship between skin colour and judgements on attractiveness affect women most, Fultz argues, since a "woman's worth is judged heavily on the basis of appearance" (21). Men who have money, education, and other forms of social capital, are considered prime to be in relationships with, while the first capital often considered when seeking out a relationship with a woman is physical attractiveness (Fultz 10). Fultz references Mark E. Hill, who conducted a study to determine if the perception of heterosexual attractiveness pervaded across genders in African Americans. Through his study, Hill found that skin colour was the second most reliable predictor of attractiveness to members of the opposite sex, as of the five skin tones of women shown to participants, the lightest category was rated the highest in perceived attractiveness by men (Fultz 13). Thus, in a society that has come to deem lighter skin as more attractive, darker-skinned African American women face disadvantages in the dating market. It follows that lighterskinned African American women are more likely to have dating successes and, therefore, are more likely to be married than darker-skinned women. In a 2009 study by Darrick Hamilton, Arthur H. Goldsmith, and William Darity Jr. on "The influence of skin shade on marriage for black females," it was found that in a multi-city survey within the United States, over twice as many light-skinned black females had been married than dark-skinned ones (Hamilton et al. 11). A connection between marriage and skin shade was drawn - as "skin shade lighten[ed] the incidence of marriage [rose]" (Hamilton et al. 6). The colonial construction of beauty ideals places darker-skinned women at a disadvantage concerning aesthetic capital in many domains, such as representation in media and perceived attractiveness, and is connected to life outcomes, such as lower chances of marrying. This paragraph has summarized the impact of colorism on African American women's beauty perception, but the discussion should not stop here. 
As previously discussed, many enslaved African Americans with light brown complexions who had the 'privilege' of working as house slaves also had the opportunity to obtain minimal education. Although the institution of slavery was abolished with the Civil War, differential treatment based on skin colour persevered in America. Lighter-skinned African Americans worked in higher socioeconomic divisions than those with dark skin, due to their jumpstart in education while enslaved. As Natalie Brown, Angela Gillem, Steven Robbins, and Rebecca Lafleur state in the study "The Effect of Black Women's Skin Tone on College Students' Ratings of Their Employability", "in the late 1800s, light-skinned men could receive Ph.D.s, whereas dark-skinned men could not" (3). Additionally, according to social studies professor Shannan M. Moore in "Colorism Among African-American Teachers", "institutions of higher learning were specifically created for the 'mulatto elite,' and so the light-skinned class traditionally valued education," almost with means to dissociate away from the 'illiterate blacks' and merge closer to the 'educated whites' (52). The existence of separate schools based on black skin tone, in which "even the curricula differed: 'mulattoes' were exposed to a broader liberal arts curriculum while darker-skinned blacks received the lower-paying vocational education tracks" (Norwood 600). This separation funnelled newly freed dark-skinned African American individuals into working, blue-collar jobs. This dynamic remains presently, where skin tone affects the socioeconomic status of dark-skinned African American women (Mathews 10).

Light complexions are more readily tied to traits of intelligence and skills because of colonial history. This means, as African American political science Ph.D. student Tayler J. Mathews explains in "The relationship between skin complexion and social outcomes," that darkskinned black women are regarded in opposition and "placed into stereotypical categories such as lazy or incompetent" (Mathews 11). These associations may be able to explain why there are a disproportionate number of light-skinned African American women in corporate positions compared to darker-skinned women.

The 'similar-to-me' effect is one example of how skin colour stratification is perpetuated. As with slave buyers looking for their own features in the black women they purchased, in corporate America, "light complexions translate as 'racially similar to whites' and therefore, white people may be more comfortable accepting light shades of African American women and less comfortable with darker African American women" (Brown et al. 9). Dark-skinned individuals are often claimed to induce feelings of unease, triggering discriminatory attitudes toward dark-skinned women in every aspect of work from the hiring process to promotional options (Brown et al. 10). Another factor weighing into the difficulty faced by dark-skinned women within corporate life is the "what is beautiful is good" effect. This effect links attractiveness to other positive characteristics, such as higher economic and education outcomes (Brown et al. 10). A study by Maddox and Grey that found that "... Black and White college students gave more positive stereotypes (i.e. attractiveness and intellect) to light-skinned compared to darkskinned women" (Brown et al. 10). Applying this to the workplace, the highlighted attractiveness given to lighter-skinned African American women would grant them more opportunity throughout corporate life. Thus, Norwood asserts that the treatment of dark-skinned African American women occupationally is worse, perhaps "explaining [...] the gap in employment between women with light and dark skin complexions" (12). According to Verna M. Keith and Cedric Herring's study "Skin Tone and Stratification in the Black Community," there is about a "17.5 percentage difference in the employment rate between black women of very dark tones and very light shades" (Keith and Herring 764). According to Brown et al.'s study, "Regardless of race, men who evaluated [a] light-skinned [female] applicant indicated a greater likelihood of hiring her than...the dark-skinned applicant" (22). 
Skin complexion also affects the socioeconomic dynamic of relationships. Study after study has shown that "light-skinned African American women marry spouses with [either] higher levels of education, higher incomes, or higher levels of occupational prestige than their darker-skinned counterparts" (Hunter 247). This phenomenon essentially allows lightskinned African American women to utilize the high status of their skin tone to obtain a high status of education, income, or occupation and marry to a similar socio-economic status, propelling light-skinned couples into greater socioeconomic success than darker-skinned black women (Hunter 237). The preference for lightskinned women over dark-skinned women is wholly sewn into the American ideological fabric, intersecting with class and social status, and assessing it as a superficial beauty issue contained within places like Hollywood is facile.

\section{III: Colorism In the 21st Century}

In this present day, we acknowledge biased media and beauty perceptions more often, and the exclusionary circle of what may be deemed beautiful is now widening to let dark-skinned black women fit into it. Now, outcry and criticism bombard cosmetic brands with foundation lines that do not cater to darker skin tones. The Lupitas and Kekes of Hollywood are present just as much as the Amandlas and Zendayas. But does this change reach the broader spheres of media, or is it merely a current, fading social movement? Can this shift even begin to reach the created socio-economic gap between light- and dark-skinned women? A study on "Skin Tones in Magazine Advertising" by Donna T. Mayo, Charles M. Mayo, and Sharika Mahdi collected and scanned multiple Vogue and Sports Illustrated magazine covers from the late '90s with black women of varying skin tones. The results found that "dark-skinned and medium-skinned African Americans [were] more dominant in both fashion and sports magazines" (Mayo et al. 56). I believe this suggests a trend towards a more frequently positive representation for dark-skinned women. Additionally, a 2018 study by Srikant Devaraj, Narda R. Quigley, and Pankaj C. Patel on "The effects of skin tone, height, and gender on earnings [in the early 2000s]" produced unexpected results that income had "no differences for women with different skin tones" (Devaraj et al. 6). It would be contentious to believe that this indicates a vanquishment of "centuries of entrenched bias and discrimination" (Devaraj et al. 18) toward darker-skinned women. Although there are "likely other mediators and/or moderators in play that should be examined in future research" (Devaraj et al. 6), this shift away from having skin tone indicate socioeconomic status and life outcomes is heartening. Nonetheless, when comparing white-owned magazines to Ebony, results found that the "majority of African Americans in the ads of Ebony had Caucasian phenotypes" (Mayo et al. 57). These results point to an unfortunate picture: even though White America may progress past the correlation of only light-skinned black women with the colonial ideals of attractiveness, it has been ingrained so deeply in the African American population that it seems more time and effort will be needed to overcome these ideals.

This essay has explored the pervasiveness of the colonial creation of colorism in the everyday lives of African American women. In order to focus on colorism's impact on dark-skinned black women, I have not touched on the other impacts of colorism, but still feel they are important enough to be mentioned. Light-skinned women have also faced discrimination due to the value placed on skin tone. These women can experience a lack of grounding to black culture, alienation from communities, and heightened fetishization in media. The colonial impacts of tests against light-skinned women and the self-identity struggle those types of tests may have caused are necessary and valid discussions (Kerr 278). Furthermore, colorism exists for African American men in a thoroughly unique lens. With desirable masculine traits of strength inferred upon the darker skinned men by slave buyers, a negative association persists around light-skinned men, describing them as "femi- 
nine" and has similarly profound impacts in their lives. However, with that feminine, gentle trait given to enslaved light-skinned men, there also lingers the reverse association for dark-skinned men as "barbaric" (Johnson 139). All of these implications point to the fact that the pervasiveness of colorism within all African American lives is still a beast, rearing its ugly head.

This essay has unwrapped the fabrication of colorism as an engrained phenomenon within Black communities by highlighting its colonial narrative in the slave markets. After the physical liberation of enslaved African American women, the use of racial testing established colorism within the Black community. I maintain that the impacts of colorism are far-reaching, not only in the aesthetic perception of African American women but also in education, perceived intelligence, romance, and socio-economic dynamics. However, the goal of this essay was not to provide solutions or ideas on how to fix colorism. Instead, I have chosen to stress the significance of its presence and the importance of contemporary racial conversations and research. It is both fascinating and disappointing that the study of colorism - with such profound impacts on individual African American lives - can remain in the spring beginnings of its sociological inquiry. It is not only due time to bring on the summer of this study, to shine a light on the issue and begin to untangle it from the fabric of American society, but also to let the start of its summer be defined by boldly stepping into the sun.

\section{Author Biography}

Adeola Egbeyemi is from Ottawa, Ontario and currently attends McMaster University in Hamilton, Ontario. She wrote this paper in her Inquiry to Global Challenges class, one of the many classes in her program, Arts and Science, that she enjoyed being, well, challenged in. There must have been some sort of foundation line controversy erupting on Instagram at that time, and it clicked in her that colorism was a contemporary issue, with much untouched historical weight - and thus, research began. She thought it would be much longer before writing a back-of-the-book author biography, so she is ridiculously grateful for the work of all the editors and for this opportunity from the University of Waterloo's Journal of Integrative Reflection and Research. 


\section{Works Cited}

Brown, Natalie, et al. "The Effect of Black Women's Skin Tone on College Students' Ratings of Their Employability: A Preliminary Study." 15 Dec. 2003, pp. 1-36., pdfs.semanticscholar.org/d22e/741cd5089403a457b27b864bda1b0e2859ad.pdf.

Bramlett, Sharon A. Race, Gender, Class and Media: Studying Mass Communication and Multiculturalism. Kendall Hunt Publishing Company, 2017.

"Ebony." Google Books, Google, books.google.ca/books/about/Ebony.html?id=PtMDAAAAMBAJ \&redir_esc $=\mathrm{y}$.

Fears, L. M. Colorism of black women in news editorial photos. The Western Journal of Black Studies, 22(1), 30-36.

Fultz, L. A. The Psycho-Social Impact of Colorism Among African American Women: Crossing the Divide. The School of Professional Psychology Wright State University,1-65.

Hamilton, Darrick, et al. "Shedding 'Light' on Marriage: The Influence of Skin Shade on Marriage for Black Females." Journal of Economic Behavior 63 Organization, 6 June 2009, pp. 1-21.

Hunter, M. The Persistent Problem of Colorism: Skin Tone, Status, and Inequality. Sociology Compass,2(1), 366-370. doi:10.1111/j.1751-9020.2007.00078.x

Johnson, Walter. Soul by Soul: Life inside the Antebellum Slave Market. Harvard University Press, 2000 .

Keith, Verna M, and Cedric Herring. "Skin Tone and Stratification in the Black Community." The University of Chicago Press, vol. 97, Nov. 1991, pp. 760-778., www.jstor.org/stable/pdf/2781783.pdf.

Kerr, A. E. The Paper Bag Principle: Of the Myth and the Motion of Colorism. Journal of American Folklore,118(469), 271-289. doi:10.1353/jaf.2005.0031.

Mathews, T. J. The relationship between skin complexion and social outcomes: how colorism affects the lives of African-American women. ETD Collection for AUC Robert W. Woodruff Library, 1-85.

Mayo, Donna T, et al. "Skin Tones in Magazine Advertising." Journal of Promotion Management, 22 Sept. 2008, pp. 49-58., doi:https://doi.org/10.1300/J057v11n02_05.

Moore, Shannan M. "Colorism Among African-American Teachers: A Qualitative Study of IntraRacial Discrimination in the Classtoom." Liberty University, 2016, pp. 1-157

Norwood, K. J. "If You Is White, You's Alright. . . ." Stories About Colorism in America. Washington University Global Studies Law Review,14(4), 585-607.

TEDx Talks. "Confessions of a D Girl: Colorism and Global Standards of Beauty — Chika OkoroTEDxStanford." YouTube, 
talk by Chika Okoro, 22 May. 2016, https://www.youtube.com/watch?v=fvoWoMIwr-g

Tharps, L. L. Same family, different colors: Confronting colorism in America's diverse families. Boston: Beacon Press.

Walker, Alice. In Search of Our Mothers Gardens: Womanist Prose. Open Road Integrated Media, 2011. 